\title{
Media Pop Up Book dalam Pembelajaran PAI untuk Meningkatkan Minat Belajar Peserta Didik
}

\author{
Dian Maryani \\ Universitas Islam Nusantara Bandung, Indonesia \\ *Coresponding Author: dianmaryani738@gmail.com
}

Article History:

Received 2021-10-21

Revised 2021-11-10

Accepted 2022-01-22

DOI:

10.31949/educatio.v8i1.1600

\begin{abstract}
One of the causes of the low quality of education is the lack of level of teacher attention to the development of teaching in schools, because teachers pay less attention to learning media. The application of learning media in the teaching and learning process of Islamic Religious Education (PAI) is a challenge in developing teacher competence. Pop up book learning media can be used as a solution as a medium in PAI learning, especially in the delivery of the story of the Prophet. This media can increase interest in learning and is liked by students because it looks attractive and makes students creative. This study was conducted to determine the use of pop up book media in learning at $\mathrm{R} A$ At-taqwa, Karawang Regency. This research is descriptive qualitative with normative, pedagogical, and psychological theological approaches. To collect data, the writer uses interview, observation, and documentation methods. The data collected were analyzed in a qualitative descriptive analysis. The results showed an increase in indicators of knowledge, enthusiasm, patience, self-control, obedience, independence and responsibility during learning. From these results it can be concluded that the use of pop up book media in PAI learning can increase students' interest in learning at $\mathrm{R} A$ Attaqwa, Karawang Regency.

Keywords: learning media; pop-up books; interest to learn
\end{abstract}

\section{PENDAHULUAN}

Pendidikan agama Islam merupakan mata pelajaran yang perlu diajarkan kepada peserta didik pada setiap jenjang pendidikan, mulai dari pendidikan usia dini sampai dengan perguruan tinggi. Tujuan utama pendidikan Islam adalah terciptanya akhlak yang baik (Darmiah, 2017). Pendidikan pada tataran wacana maupun dalam praktiknya merupakan proses humanisasi, yakni memanusiakan manusia atau proses kedewasaan manusia menuju terbentuknya manusia paripurna (insan kamil) pencapaian kamanusiaan yang 
sejati. Pembentukkan manusia paripurna dijadikan sebagai tujuan yang ingin dicapai dalam proses pendidikan untuk menjadi fokus perhatian utama dalam pelaksanaan itu sendiri.

Salah satu penyebab rendahnya mutu pendidikan adalah kurangnya tingkat perhatian guru terhadap pengembangan pengajaran di sekolah, karena guru kurang memperhatikan media pembelajaran. Penerapan media pembelajaran dalam proses belajar mengajar pendidikan agama Islam merupakan suatu tantangan dalam mengembangkan kompetensi guru. Relevansinya dengan meningkatkan pemahaman dan minat peserta didik pada pendidikan agama Islam dalam pengembangan kompetensi guru merupakan salah satu faktor penunjang utama dalam sistem pendidikan. Dengan demikian kompetensi guru sangat penting bagi keberhasilan pencapaian tujuan pendidikan atau peningkatan prestasi peserta didik. Guru adalah figur sentral dalam dunia pendidikan, khususnya saat terjalinnya proses interaksi pembelajaran dengan menggunakan media sebagai sarana dalam meningkatkan pemahaman peserta didik. Oleh karena itu, guru harus melakukan inovasi pendidikan, khususnya dalam media pembelajaran. Dalam memilih media pembelajaran pendidikan Agama Islam, hal yang perlu dilakukan adalah ketepatan dalam memilih, menentukan mana di antara sekian media pembelajaran itu lebih cepat dan cocok untuk diterapkan dalam situasi pengajaran.

Pendidikan anak usia dini merupakan salah satu bentuk penyelenggaraan pendidikan yang menitikberatkan pada peletakan dasar kearah pertumbuhan dan perkembangan fisik (koordinasi motorik halus dan kasar), kecerdasan daya cipta, kecerdasan emosi dan kecerdasan spiritual (Purnamasari, 2013). Anak usia dini adalah sosok individu yang sedang menjalani suatu proses perkembangan dengan pesat dan fundamental bagi kehidupan selanjutnya (Agustina et al, 2018). Seorang anak pada usia dini perlu diperkenalkan pendidikan agama untuk membentuk pribadi yang kuat berlandaskan agama dalam hal mendidik anak (Jasuri, 2015). Karena pada usia ini merupakan masa- masa terpenting bagi pertumbuhan dan perkembangan anak. Sehingga perlu ditanamkan nilai-nilai agama sejak dini agar dapat terbentuk kepribadian anak yang Islami. Selain itu merupakan masa penentu keberhasilan anak di masa mendatang.

Pendidikan Agama Islam (PAI) merupakan upaya sadar dan terencana dalam menyiapkan anak untuk mengenal, memahami, menghayati, hingga mengimani ajaran agama Islam (Ahmad \& Tambak, 2017; Elihami \& Syahid, 2018; Maftuhin \& Fuad, 2018; Utari et al, 2020). PAI RA juga menekankan pembelajaran untuk menghormati penganut agama lain dalam rangka mewujudkan kerukunan antar umat beragama. Pembelajaran PAI RA berbasis disiplin ilmu yang meliputi Al-Qur'an-Hadis, akidah, akhlak, ibadah dan kisah Islami yang disampaikan secara terpadu.

Dalam proses penyampaian pembelajaran Pendidikan Agama Islam (PAI), di RA At-Taqwa memadukan berbagai metode pengajaran yang cocok untuk jenjang usia dini. Metode-metode tersebut di antaranya metode bermain, metode bercerita, metode menyanyi/ musik, metode karya wisata, dan metode demonstrasi. Metode-metode tersebut bisa diterapkan secara efektif dengan ditunjang media pembelajaran sesuai dengan materi yang akan disampaikan. Guru-guru di Ra At-taqwa sering melakukan pelatihan mengenai media pembelajaran sehingga proses pembelajaran menjadi lebih kreatif, inovatif dan menyenangkan. Alasan inilah yang menjadi penyebab peneliti melakukan penelitian di RA At-Taqwa.

Salah satu media pembelajaran yang digunakan untuk penyampaian materi PAI di RA At-Taqwa yaitu pop up book. Media Pop-Up Book merupakan sebuah buku tiga yang memiliki unsur 3 dimensi yang dapat bergerak saat halaman dibuka, serta memberikan visualisasi maupun tampilan yang lebih menarik untuk meningkatkan pemahaman siswa terkait materi (Ari \& Handriyotopo, 2020; Setiyanigrum, 2020; Ulfa \& Nasryah, 2020; Umam et al, 2019). Buku ini menampilkan potensi untuk bergerak dan interaksinya melalui penggunaan kertas sebagai bahan lipatan, gulungan, bentuk, roda, atau putarannya (Dewanti et al, 2019; Hanifah, 2014; Restianim etal, 2020). Media ini sangat disukai anak-anak, karena selain penampilannya menarik, juga membuat anak-anak lebih kreatif.

Berdasarkan latar belakang tersebut, penelitian ini bertujuan ingin mengetahui penggunaan media Pop Up Book dalam pembelajaran PAI untuk meningkatkan minat belajar peserta didik di RA At-taqwa Karawang. 


\section{METODE PENELITIAN}

Jenis penelitian ini adalah deskriptif kualitatif dengan pendekatan teologis normatif, pedagogis, dan psikologi. Lokasi penelitian ini adalah di RA At-Taqwa Karawang. Adapun sumber data pada penelitian ini adalah ada dua sumber data, data primer yaitu wakil kepala sekolah, guru, dan peserta didik sedangkan data sekunder adalah dokumen RPP yang terkait dengan objek yang diteliti. Data diperoleh melalui observasi, wawancara dan dokumentasi. Data selanjutnya dianalisis secara kualitatif dengan menggunakan triangulasi untuk memastikan validitas data terhadap fokus yang diteliti. Hasil penelitian menunjukkan bahwa pelaksanaan penyampaian materi pendidikan agama Islam pada jenjang pendidikan pra sekolah (RA) dengan media pembelajaran pop up book, sangat menarik perhatian anak. Mereka jadi mudah memahami materi yang mempunyai muatan ibadah. Dengan pembelajaran muatan ibadah anak dari usia dini diharapkan dapat menjadi anak yang taat beribadah, jujur, sopan santun, toleran, mandiri, tanggung jawab, dan rendah hati.

\section{HASIL DAN PEMBAHASAN}

\section{Tujuan Penggunaan Media Pembelajaran PopUp Book}

Tujuan penggunaan media pop up book dalam pembelajaran PAI untuk meningkatkan minat belajar peserta didik di RA At-taqwa karawang, yaitu untuk mengetahui efektifitas media pop up book dalam proses pembelajaran. Menurut UU Sisdiknas No. 20 tahun 2003 pasal 40; 2, pendidik dan tenaga kependidikan berkewajiban menciptakan Suasana pendidikan yang dekat, menyenangkan, kreatif, dinamis dan dialogis. Untuk menerapkan apa yang tertulis dalam Undang-undang Sisdiknas dalam pembelajaran, guru tidak bisa mengajar hanya dengan menggunakan metode ceramah. Hal tersebut dapat membuat siswa merasa bosan karena siswa tidak memahami apa yang disampaikan oleh guru. Maka, untuk mengatasi hal tersebut penggunaan media sebagai alat bantu mengajar sangat dibutuhkan.

Selain dari hasil observasi lapangan, peneliti juga melakukan wawancara kepada beberapa pihak yang dapat memberikan informasi mengenai permasalahan yang berkaitan dengan penggunaan media pop up book ini. Dari hasil wawancara tersebut didapatkan hasil yaitu guru yang akan melakukan proses belajar mengajar terlebih dahulu harus membuat sebuah program yang sesuai dengan standar pemerintah.

Dalam pencapaian sebuah target pembelajaran guru juga harus menyesuaikan dengan beberapa hal yang termaktub dalam rencana pelaksanaan pembelajaran (RPP). Sebelum masuk ke inti pembelajaran, guru wajib menyampaikan apa tujuan materi yang akan disampaikan, serta guru harus melakukan pembelajaran dengan ice breaking yang menyenangkan sehingga peserta didik semangat untuk belajar. Dari hasil penyesuaian antara guru dengan peserta didik diharapkan dapat menjalankan proses pembelajaran dengan aktif, kreatif dan menyenangkan.

Dilihat dari kondisi saat ini dimana kita masih berada dimasa pandemic covid -19, maka untuk proses pembelajaran banyak dilakukan secara daring. Tetapi, dikarenakan usia peserta didik masih berkisar antara 4-5 tahun diperlukan bimbingan dari guru dan orang tua, jadi proses pembelajaran dilakukan pula secara tatap muka. Jumlah peserta didik yang hadir hanya $50 \%$ dari keseluruhan siswa dan waktu belajar hanya berkisar sekitar 2 jam dengan memberlakukan protokoler Kesehatan secara ketat. Pembiasaan tertib protokoler Kesehatan sejak dini akan melatih anak untuk disiplin menjaga kesehatan dan mentaati peraturan sekolah.

Meskipun pembelajaran dilaksanakan secara daring, namun tidak menyurutkan semangat dan antusias peserta didik untuk mengikuti kegiatan yang diadakan sekolah. Kerja sama dari orang tua untuk membantu membimbing ketika pembelajaran di rumah, sangat menentukan keberhasilan penyampaian materi dan pemahaman oleh peserta didik. Guru di RA At-taqwa Kabupaten Karawang tidak henti-hentinya memberikan motivasi kepada peserta didik dan orang tua siswa supaya tidak putus asa dan stress ketika mendampingi pembelajaran di rumah. Sekolah pun berusaha memberikan kegiatan parenting yang dilaksanakan secara online melalui aplikasi zoom untuk memperkuat mental orang tua mendampingi anak ketika daring.

Penggunaan pop up book di RA At-taqwa Kabupaten Karawang belum bisa dilakukan secara daring dikarenakan perlu ada komunikasi interaktif antara peserta didik dengan guru secara langsung. Penyampain materi PAI tentang kisah Nabi dilakukan secara langsung atau tatap muka sehingga peserta didik bisa secara 
langsung dalam pembelajaran. Melalui penggunaan pop up book ini diharapkan dapat membentuk peserta didik yang kreatif, antusias, rasa ingin tahu yang tinggi, sabar, bisa mengendalikan diri taat, mandiri serta bertanggung jawab, sehingga dapat membentuk peserta didik yang berilmu dan beramal sholeh dalam kehidupan sehari-hari sesuai dengan visi dan misi RA At-taqwa Kabupaten Karawang.

2. Pelaksanaan Penggunaan Media Pembelajaran Pop Up Book

Pelaksanaan penggunaan media pembelajaran $p \circ p$ up book merupakan salah satu bagian dari perencanaan pembelajaran yang tersusun di rencana kegiatan harian (RKH). Rencana kegiatan harian merupakan penjabaran dari rencana kegiatan mingguan (RKM), isinya memuat kegiatan-kegiatan yang dilaksanakan secara individual, kelompok maupun klasikal dalam satu hari. Komponen-komponen dalam RKH terdiri dari indikator pembelajaran, tujuan pembelajaran, kegiatan, materi pembelajaran, motede, media dan karakter bangsa yang ingin dikembangkan.

Dalam pelaksanaan pembelajaran, tugas guru yang paling utama adalah mengkondisikan lingkungan agar menunjang terjadinya perubahan perilaku bagi peserta didik. Umumnya pelaksanaan pembelajaran mencakup tiga hal yaitu pre test, proses, dan post tes (Mulyasa, 2006:100). Proses pembelajaran perlu dilakukan dengan tenang dan menyenangkan, hal tersebut tentu saja menuntut aktivitas dan kreativitas guru dalam menciptakan lingkungan yang kondusif. Proses pembelajaran dikatakan efektif apabila seluruh peserta didik terlibat secara aktif, baik mental, fisik maupun sosialnya.

Untuk menunjang berhasilnya materi PAI dipahami peserta didik di RA At-taqwa Karawang, guru mempunyai inisiatif menggunakan media pop up book. Media ini terbukti dapat meningkatkan minat belajar peserta didik. Hal tersebut dapat terlihat ketika guru akan memulai pembelajaran. Saat guru menunjukan sebuah buku yang berbentuk 3 dimensi dan gambanrnya dapat digerakkan, peserta didik sangat tertarik dan ingin ikut mencoba menggunakan buku tersebut.

Dalam menyampaikan materi kisah Nabi di RA At-taqwa Karawang menggunakan metode demonstrasi dengan media pор ир book. Dengnan media ini, peserta didik antusias mengikuti pembelajaran. Selain metode demonstrasi, menggunakan pula metode lain seperti bermain peran, bercerita dan bernyanyi. Penggunaan media рор ир book selain membuat guru lebih kreatif juga mengajarkan peserta didik turut kreatif pula. Dari wawancara yang dilakukan kepada guru RA At-taqwa Karawang bahwa mereka dalam setiap pembelajaran harus menyampaikan Standar Tingkat Pencapaian Perkembangan Anak (STPPA) yaitu: moral, agama, social, emosional, kognitif, Bahasa, fisik motorik dan seni.

3. Hasil (evaluasi) Penggunaan Media Pembelajaran Pop Up Book

Hasil dari penggunaan media pop up book di RA At-taqwa Karawang dapat menarik dan meningkatkan minat peserta didik. Hal ini dapat terlihat dari antusias peserta didik ketika guru mulai menunjukan buku berbentuk 3 dimensi yang dapat digerakkan. Dengan warna yang menarik, membuat peserta didik timbul rasa penasaran dan banyak bertanya mengenai media рор up book ini. Respon positif dari peserta didik secara tidak langsung dapat mengalihkan fokus anak untuk memperhatikan media dan materi serta cerita yang akan disampaikan, sehingga tujuan pembelajaran yang tertuang dalam RKH dapat terlaksana dan tercapai sesuai dengan yang diharapkan.

4. Faktor Pendukung dan Penghambat dalam Penggunaan Media Pembelajaran Pop Up Book

Proses penggunaan media pop up book dalam pembelajaran PAI untuk meningkatkan minat belajar peserta didik di RA At-taqwa Karawang memiliki faktor pendukung dan penghambat dalam pelaksanaannya. Adapun yang mendukung penggunaan media pop up book ini di antaranya adalah: (1) Motivasi dari sekolah untuk semua guru dalam mengikuti pelatihan dan seminar sebagai wujud peningkatan kualitas diri; (2) Menambah kreatifitas guru dan mengurangi biaya pembelian media pembelajaran; (3) Peningkatan kualitas sekolah. Sedangkan faktor penghambat dalam penggunaan media pop up book ini adalah: (1) Biaya yang cukup mahal untuk membeli alat dan bahan; (2) Waktu yang relatif lama dalam pembuatannya; (3) Diperlukan kreatifitas tinggi serta keuletan untuk menghasilkan media pop up book yang bagus dan menarik.

Dari hasil penelitian tersebut diperoleh temuan bahwa penggunaan media pembelajaran pop up book di RA At-Taqwa Karawang pada materi kisah Nabi Yunus, menunjukkan peningkatan minat pada peserta didik. Hal tersebut ditunjukkan dengan adanya perubahan pada diri peserta didik, seperti antusias terhadap 
materi pembelajaran yang disampaikan, bertambahnya pengetahuan, sabar, pengendalian diri, taat dan bertanggung jawab, sehingga menghasilkan siswa yang berilmu dan beramal sholeh. Faktor pendukung dan penghambat dalam penggunaan media pembelajaran pop up book di RA At-Taqwa Karawang pada materi kisah Nabi Yunus, yaitu adanya dukungan dari kepala sekolah terhadap guru untuk terus meningkatkan kemampuan dan keterampilannya dalam membuat media pembelajaran. Sedangkan faktor penghambatnya yaitu rentang waktu yang cukup lama dalam pembuatan media pop-up book, biaya yang cukup besar apabila media tersebut harus dibeli dan kemampuan guru dalam menyampaikan materi terutama kisah Nabi yang mengharuskan guru bisa bercerita. Temuan penelitian ini mendukung hasil penelitian sebelumnya yang dilakukan oleh Alamsyah \& Purba (2020), Alfiyanti (2021), dan Paramita \& Ernawati (2020) yang menunjukkan hasil bahwa adanya peningkatan minat belajar siswa dalam pembelajaran menggunakan media pop up book.

\section{KESIMPULAN}

Penggunaan media pembelajaran pop up book dapat meningkatkan minat pada peserta didik di RA AtTaqwa Karawang pada materi kisah Nabi Yunus. Dari hasil observasi diperoleh adanya perubahan pada diri peserta didik, siswa lebih antusias dalam pembelajaran, bertambahnya pengetahuan, sabar, pengendalian diri, taat dan bertanggung jawab, sehingga menghasilkan siswa yang berilmu dan beramal sholeh. Dalam penggunaan media pembelajaran pop up book di RA At-Taqwa Karawang pada materi kisah Nabi Yunus, kepala sekolah mendukung penuh guru untuk terus meningkatkan kemampuan dan keterampilannya dalam membuat media pembelajaran.

\section{DAFTAR PUSTAKA}

Agustina, S., Nasirun, M., \& Delrefi, D. (2018). Meningkatkan Keterampilan Motorik Halus Anak Melalui Bermain Dengan Barang Bekas. Jurnal Ilmiah Potensia, 3(1), 24-33.

Ahmad, M. Y., \& Tambak, S. (2017). Hubungan metode tanya jawab dengan minat belajar peserta didik pada mata pelajaran Pendidikan Agama Islam. Jurnal Pendidikan Agama Islam Al-Thariqah, 2(1), 89-110.

Alamsyah, M. S., \& Purba, R. (2020). Meningkatkan Minat Belajar Thaharah Dalam Membersihkan Najis Dan Hadas Untuk Tingkat Mts Dengan Media Pop-Up Book. Jurnal Mahasiswa Fakultas Seni dan Desain, 1(1), 117-132.

Alfiyanti, N. (2021). Pengaruh Penggunaan Media Pop-Up Book Terhadap Minat Belajar Ipa (Studi Eksperimen terhadap Siswa kelas V SDN 1 Cibunar). caXra: Jurnal Pendidikan Sekolah Dasar, 1(2), 7381.

Ari, I. M. A., \& Handriyotopo, H. (2020). Perancangan Pop Up Book And Sound Tembang Dolanan Sebagai Media Pengenalan Alat Musik Gamelan. Citrawira: Journal of Advertising and Visual Communication, 1(1), $22-43$.

Darmiah, D. (2017). Strategi Pembelajaran Pendidikan Agama Islam di Sekolah Lanjutan Menengah Atas dan Pengaruhnya Terhadap Pembangunan Karakter. PIONIR: Jurnal Pendidikan, 6(1).

Dewanti, H., Toenlioe, A. J., \& Soepriyanto, Y. (2019). Pengembangan Media Pop-Up Book Untuk Pembelajaran Lingkungan Tempat Tinggalku Kelas Iv Sdn 1 Pakunden Kabupaten Ponorogo. Jurnal Kajian Teknologi Pendidikan, 1(3), 221-228.

Elihami, E., \& Syahid, A. (2018). Penerapan Pembelajaran Pendidikan Agama Islam Dalam Membentuk Karakter Pribadi Yang Islami. Edumaspul: Jurnal Pendidikan, 2(1), 79-96.

Hanifah, T. U. (2014). Pemanfaatan media pop-up book berbasis tematik untuk meningkatkan kecerdasan verbal-linguistik anak usia 4-5 tahun (studi eksperimen di TK negeri pembina bulu temanggung). BELLA: Early Childhood Education Papers, 3(2).

Jasuri, J. (2015). Pembelajaran Pendidikan Agama Islam pada Anak Usia Dini. Madaniyah, 5(1), 195070.

Maftuhin, M., \& Fuad, A. J. (2018). Pembelajaran Pendidikan Agama Islam Pada Anak Berkebutuhan Khusus. Journal An-Nafs: Kajian Penelitian Psikologi, 3(1). 
Paramita, O., \& Ernawati, T. (2020). Pengaruh Penggunaan Media Pop-Up Terhadap Minat dan Hasil Belajar IPA Siswa Kelas IV SD Singosaren. TRIHAYU: Jurnal Pendidikan Ke-SD-An, 6.

Purnamasari, W. W. (2013). Studi Perbandingan Pengembangan Layanan Paud Di Kecamatan Brebes Dan Di Kecamatan Bulakamba Kabupaten Brebes. Indonesian Journal Of Early Childhood Education Studies, 2(2).

Restianim, V., Sar'Tyyah, N., \& Novianti, C. (2020). Penggunaan My Pop Up Book Ditinjau dari Hasil Belajar Matematika Siswa Sekolah Dasar. SPEJ (Science and Physic Education Journal), 4(1), 9-14.

Setiyanigrum, R. (2020). Media Pop-Up Book sebagai Media Pembelajaran Pascapandemi Covid-19. In Prosiding Seminar Nasional Pascasarjana (PROSNAMPAS) (Vol. 3, No. 1, pp. 216-220).

Ulfa, M. S., \& Nasryah, C. E. (2020). Pengembangan Media Pembelajaran Pop-Up Book Untuk Meningkatkan Motivasi Belajar Siswa Kelas IV SD. Edunesia: Jurnal Ilmiah Pendidikan, 1(1), 10-16.

Umam, N. K., Bakhtiar, A. M., \& Iskandar, H. (2019). Pengembangan Pop Up Book Bahasa Indonesia Berbasis Budaya Slempitan. Trapsila: Jurnal pendidikan dasar, 1(02), 1-11.

Utari, L., Kurniawan, K., \& Fathurrochman, I. (2020). Peran Guru Pendidikan Agama Islam dalam Membina Akhlak Peserta Didik Autis. JOE AI: Journal of Education and Instruction, 3(1), 75-89. 